Oliveira, M.T.C.; Alves, P.A.G. Análise do potencial para implantação de atividades de observação de aves no cerrado paulista: Parque Estadual do Juquery, Caieiras e Franco da Rocha (SP). Anais do VIII Congresso Nacional de Ecoturismo e do IV Encontro Interdisciplinar de Ecoturismo em Unidades de Conservação. Revista Brasileira de Ecoturismo, São Paulo, v.4, n.4, 2011, p. 549.

\title{
ANÁLISE DO POTENCIAL PARA IMPLANTAÇÃO DE ATIVIDADES DE OBSERVAÇÃO DE AVES NO CERRADO PAULISTA: PARQUE ESTADUAL DO JUQUERY, CAIEIRAS E FRANCO DA ROCHA (SP)
}

\author{
Marcelo Teixeira Cesar de Oliveira*, Patrícia Adalgisa Gobitti Alves* \\ *Instituto Ipá Ti-uá de Meio Ambiente, Cultura e Sociedade, \\ E-mails: marcelotco@ipatiua.com.br, birdwatcher@ipatiua.com.br
}

A observação de aves é um segmento do Ecoturismo dentre outros de observação de fauna existentes no mundo. O Brasil é o segundo país em diversidade de aves. No país, está em franco crescimento e contando com apoio da EMBRATUR e do Ministério do Turismo em algumas iniciativas. Apesar de que muitos locais tem potencial, a atividade ainda é muito pouco explorada. Assim, é importante identificar áreas para a atividade, considerando este potencial e sua viabilidade. Questões como acesso, infra-estrutura, estado de conservação e a composição da avifauna devem ser considerados. O Parque Estadual do Juquery, nos municípios de Caieiras e Franco da Rocha, SP, possui uma biodiversidade representativa de cerrado paulista com 250 espécies catalogadas de plantas e 154 de aves. Esta Unidade de Conservação é o último fragmento de cerrado da Região Metropolitana de São Paulo (RMSP). Com diferentes fisionomias de vegetação num mosaico de formações de cerrado, predominam as formas campestres mais abertas dos tipos campo-sujo, campo-cerrado e campo-limpo. Sua criação, pelo Decreto Estadual no 36.859/93, teve como objetivo principal proteger esta formação vegetal numa área total de 2.058,09 ha. Nos grotões, entre os morros e na parte baixa das encostas existem também fragmentos de formações florestais, além de uma região com lagos. Situada entre as coordenadas $23^{\circ} 21^{\prime} \mathrm{S}$ e $46^{\circ} 42^{\prime} \mathrm{W}$, apresenta relevo composto por grandes morros com altitudes por volta de $900 \mathrm{~m}$. O objetivo deste trabalho foi analisar o potencial para implantação de atividades de ecoturismo e educação ambiental focadas na observação de aves nesta área de cerrado. Foi realizada pesquisa bibliográfica e webgráfica, levantamento local - entre março de 2009 a dezembro de 2010 - através de registros fotográficos, observação e anotações de campo compostas também de relato de técnicos do Parque. O acesso a área é bastante fácil e a infraestrutura para visitantes está centralizada numa pequena instalação onde funciona o núcleo de Educação Ambiental com auditório para 60 pessoas, multimídia, museu com moldes de pegadas, animais taxidermizados, vitrine com cerrado reconstituifo e painéis explicativos sobre a fauna, flora, história e o tráfico de animais. As trilhas possuem placas indicativas com informações como nome da trilha, grau de difuldade, total do percusso e tempo estimado. Não apresentam regras de visitação e nem informações sobre características ambientais locais. As trilhas percorridas são trilhas curtas e circulares onde volta-se ao ponto inicial sem repetir o percurso de retorno e com sentido único para que o visitante não encontre outros no sentido contrário. Também possui torre de observação e diversos pontos elevados que facilitam a observação de aves, principalmente as rapinantes. Em todos os percurssos conta-se com apoio de funcionários munidos de motos garantindo a segurança. A região apresenta bom potencial para a atividade pelo acesso fácil por estrada asfatada, por apresentar condições favoráreis de infra-estrutura, ter um número significativo de espécies típicas de aves de cerrado, ter bons pontos de observação em ambientes diversificados, ter formações abertas e apresentar trilhas circulares curtas que favorecem 0 caráter educativo e o trabalho de interpretação ambiental.

Palavras chaves: Aves; Ecoturismo; Educação Ambiental. 